\title{
Нові можливості діагностики оніхомікозу за допомогою дерматоскопії
}

\author{
Г.С. Стовбир \\ Національна медична академія післядипломної освіти імені П.Л. Шупика
}

\begin{abstract}
Резюме
Оніхомікоз є одним з найпоширеніших захворювань нігтів, на яке припадає близько 50\% усіх захворювань нігтьового апарату. Класичні методи діагностики (мікроскопія та культуральна діагностика) можуть бути хибно негативними в 35\% випадків, що обумовлює необхідність пошуку додаткових діагностичних методів. До таких методів можна віднести дерматоскопію. Нині немає чіткого алгоритму дерматоскопічних ознак, описаних і підтверджених для оцінювання оніхомікозу.

Метою роботи було встановлення специфічних дерматоскопічних ознак грибкового ураження нігтів.

Результати та висновки. Враховуючи літературні дані та власні спостереження, можна зробити висновок, що за допомогою дерматоскопіі, зокрема, можна побачити відмітні ознаки, які є винятковими для дистально-латерального піднігтьового оніхомікозу (DSLO), травматичного оніхолізису і дають змогу провести диференційну діагностику з іншими захворюваннями нігтьового апарату.
\end{abstract}

Ключові слова: оніхомікоз, діагностика, дерматоскопія.

DOI: 10.33743/ 2308-1066-2019-3-34-36

Оніхомікоз є одним з найпоширеніших захворювань нігтів, на яке припадає близько 50\% усіх захворювань нігтьового апарату. Серед шкірних захворювань його частка становить 0,44\% [9]. Диференційна діагностика оніхомікозу охоплює запальні (псоріаз, алопеція), системні (амілоїдоз, діабет, порфірія), інфекційні захворювання, що можуть імітувати оніхомікоз (вірусні бородавки і хронічні пароніхіі) тощо. Також можлива механічна травматизація, тож необхідно диференціювати грибкове ураження нігтів з косметичною травмою (манікюр або педикюр), вторинною травмою (тугі туфлі або тертя) і пухлинами нігтьового апарату (плоскоклітинна карцинома, меланома або фіброма) [10]. Методи лікування цих захворювань істотно відрізняються. Лікування оніхомікозу може тривати багато місяців, бути економічно затратним і супроводжуватися тяжкими побічними явищами, тому встановлення точного діагнозу є важливим [2].

Натепер основою діагностики грибкового ураження нігтів є візуальний огляд, мікроскопія з $\mathrm{KOH}$ або $\mathrm{NaOH}$, культуральна діагностика та ПЛР [2]. Їх чутливість і специфічність становлять відповідно 72-80/72-76\% для мікроскопії з КОН і 20-53/82-100\% для культуральної діагностики; ПЛР: чутливість - 86,9\% зі зниженою специфічністю - 75,6\%. Результати аналізів можуть значно варіювати в залежності від досвіду лаборанта-міколога, правильності забору матеріалу, якості апаратури та підбору середовища для вирощування культури [6]. Тести золотого стандарту можуть бути хибно негативними в 35\% випадків [4].

Той факт, що мікроскопія і культуральна діагностика не завжди є високочутливими при виявленні оніхомікозу, а ПЛР в нашій країні рідко застосовується, обумовлює необхідність пошуку додаткових діагностичних інструментів, які підвищать якість діагностики. До таких можна віднести дерматоскопію - неінвазивний метод, що широко використовується для діагностики новоутворень як шкіри, так і нігтьових пластин. Алгоритм дерматоскопіі в разі оніхомікозу був описаний B.M. Piraccini та ін. [8], демонструючи високу чутливість і специфічність при диференціації оніхомікозу від травматичного оніхолізису. Згідно з їхніми дослідженнями можна ідентифікувати три повторювані специфічні дерматоскопічні ознаки, дві з яких характерні лише для дистально-латерального піднігтьового оніхомікозу (зубчастий проксимальний край з шипами в оніхолітичній ділянці і поздовжні борозни; рис. 1, 2), а один - лише для травматичного оніхолізису (край оніхолітичної ділянки - лінійний, без шипів; рис 3).

Nakamura R.C., Costa M. опрацювали дерматоскопію оніхомікозу в 502 пацієнтів і описали непрозорість дистальних смуг при цій патології [9]. Було відмічено, що в разі дистально-латерального оніхомікозу спостерігають різкі поздовжні білі смужки. Було припущено, що вони обумовлені напрямком росту грибів. Процес починається від дистального краю нігтьової пластини і поширюється проксимально, несиметрично й нерегулярно.

M.A. Jesús-Silva та співавт. у 178 осіб проводили кореляцію між мікроскопічними та дерматоскопічними дослідженнями пацієнтів 3 клінічним діагнозом оніхомікозу. Автори виділяють наявність «шипів», що характеризуються як поглиблення на проксимальному краї ділянки оніхолізису при оніхомікозі, у порівнянні 3 «лінійним краєм» у вигляді гладенької лінійної демаркації без заглиблень у разі травматизації. «Поздовжні борозни» були 


\section{КЛІНІЧНІ СПОСТЕРЕЖЕННЯ}

вивчені та ідентифіковані як прояв прогресування дерматофітів уздовж нігтьової пластини, що свідчить про зміни забарвлення вторинної колонії або розм'якшення тканин піднігтьового гіперкератозу [5].

Tulika Ashokkumar Yadav та співавт. [11] найпоширенішими ознаками так само відзначали поздовжні борозни й зубчасті шипи. Іншими додатковими ознаками були піднігтьовий гіперкератоз і пароніхія.

Я.Ф. Кутасевич зі співавт. [1] використовували дерматоскопію для виявлення ранніх характерних ознак і структурних змін в уражених міцелієм нігтьових пластинках, оцінки ступеня тяжкості оніхомікозу і призначення своєчасної адекватної терапії. Головними дерматоскопічними критеріями, за якими оцінювався ступінь ураження та тяжкість процесу, були деформація пластинки й нігтьового ложа; наявність тунелів у товщі нігтьової пластинки; атрофія нігтьової пластинки тощо.

Таким чином, нині немає чіткого алгоритму, описаного і підтвердженого для оцінювання оніхомікозу.

Мета роботи - встановлення специфічних дерматоскопічних ознак грибкового ураження нігтів.

\section{Матеріали та методи дослідження}

За результатами наших спостережень було проаналізовано 30 випадків (15 з діагнозом оніхомікоз, дистально-латеральний тип ураження, що був підтверджений за допомогою мікроскопії та/або культурального методу діагностики, та 15 випадків з негативним результатом на паразитарні гриби та зміною нігтьової пластинки за типом оніхолізису). За допомогою дерматоскопії (оніхоскопіі) багато деталей (патернів) нігтя можуть бути збільшені і об'єднані з даними клінічного огляду для встановлення діагнозу. Нігтьову пластинку в цілому видно тільки зі збільшенням $\times 10$, але спостереження може бути покращено при збільшенні в діапазоні від $\times 20$ до $\times 70$ та поступовим переміщенням об'єктива по всій площі нігтя. У більшості випадків дерматоскопія нігтя дає змогу краще візуалізувати симптоми та зміни в нігтьовій пластинці [10].

Оніхоскопія може бути виконана без імерсії або за допомогою використання імерсійного гелю (ультразвукового гелю), імерсійного масла або спиртового розчину. Дерматоскопія без імерсії використовується для вивчення структури поверхні нігтьової пластинки (для оцінки шорсткості). Дерматоскопія з імерсією використовується, як правило, для оцінки пігментації нігтьової пластинки, оніхолізису, дистального краю нігтьової пластинки. Використання гелю так само необхідно для огляду гіпоніхію та навколонігтьових складок [7].

\section{Результати та ї обговорення}

У групі пацієнтів з оніхомікозом з 15 чоловік, що мали мікологічне підтвердження, 12 пацієнтів мали позитивний результат мікроскопії, 8 - позитивний результат культуральної діагностики. У 2 пацієнтів збудниками були дерматофіти (Trichophyton rubrum i Trichophyton mentagrophytes), у 5 - було виявлено недерматофітні плісняві гриби (Aspergillus niger у 1 пацієнта, Scopulariopsis brevicaulis - у 2 і Alternaria alternata - у 2), у 8 пацієнтів будо виявлено дріжджові гриби (Candida albicans - у 6, Candida tropicalis - у 2 випадках).

У всіх пацієнтів з підтвердженим оніхомікозом спостерігались шипи, поглиблення, спрямовані до проксимальної складки нігтьової пластинки, на проксимальному краю оніхолітичної ділянки, у 12 пацієнтів спостерігали поздовжні смуги білого та жовтуватого кольору в оніхолітичній зоні. У пацієнтів з негативними мікологічними аналізами демаркаційна лінія оніхолізису була пряма. Зміну кольору нігтьової пластинки спостерігали як у пацієнтів з підтверженим оніхомікозом (14 пацієнтів), так і пацієнтів з оніхолізисом без грибкового патогена, але в меншій кількості (4 пацієнти).

У всіх випадках оніхомікозу, підтвердженого за допомогою мікроскопії та культуральної діагностики, дерматоскопічно спостерігали шипи на проксимальній ділянці оніхолітичної зони нігтів, що можна вважати патогномонічною ознакою при дистально-латеральній формі оніхомікозу (DSLO), враховуючи огляд літератури та попередні дослідження. Поздовжні смуги також були частою значимою ознакою у пацієнтів з позитивним результатом мікологічного дослідження. У пацієнтів 3 негативними аналізами на гриби дана ознака не спостерігалась. Зміну кольору нігтьової пластинки не можна віднести до патогномонічних ознак, оскільки вона спостерігалась в обох групах, але в пацієнтів

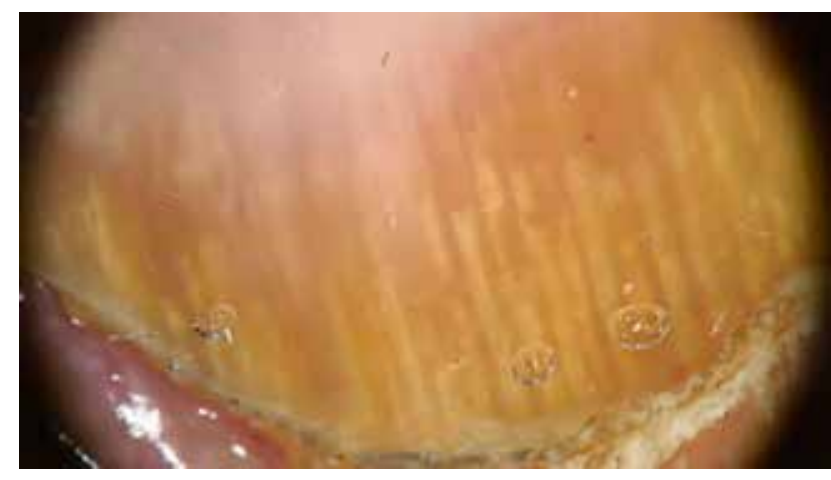

Рис. 1. «Зазубрений край», «поздовжні смуги» при дистальнолатеральному оніхомікозі

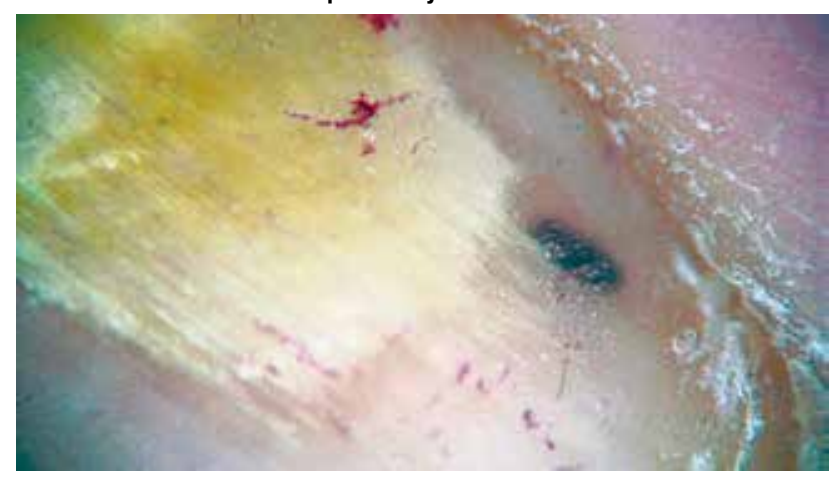

Рис. 2. «Поздовжні смуги» при підтвердженому дистальнолатеральному оніхомікозі

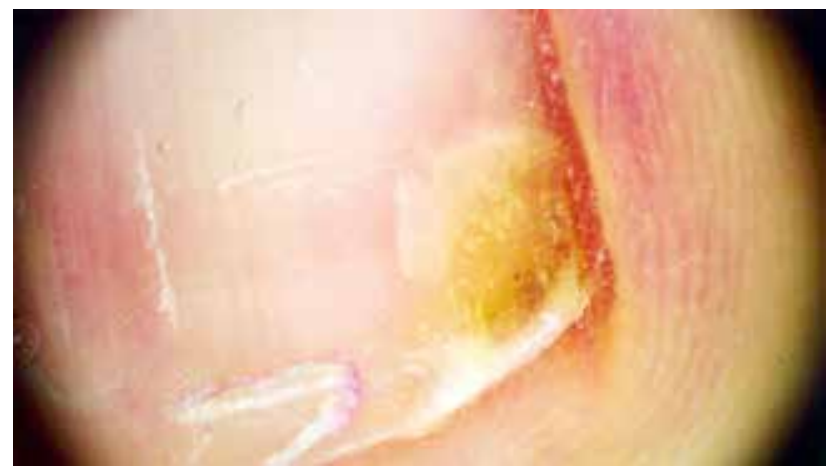

Рис. 3. Рівний край при посттравматичному оніхолізисі. Результат мікроскопічного дослідження на гриби негативний 
3 оніхомікозом дана ознака спостерігалась значно частіше. Дані наших спостережень корелюють з результатами інших досліджень, що дає змогу використовувати наведені дерматоскопічні ознаки як ознаки, специфічні для оніхомікозу.

\section{Висновки}

Мікологічне обстеження, як і раніше, залишається стандартом діагностики оніхомікозу. Водночас дерматоскопія вже є частиною діагностичної процедури

\section{Список літератури}

1. Кутасевич Я.Ф., Олейник И.А., Белозоров А.П. Современный взгляд на диагностику и лечение дерматомикозов. Медицинская газета “Здоров'я України 21 сторіччя". 2016. № 18 (391)

2. Allevato M A. Diseases mimicking onychomycosis. Clin Dermatol. 2010. № 28(2). P. 164177. doi:10.1016/j.clindermatol.2009.12.001.

3. Ameen M., Lear JT., Madan V. British Association of Dermatologists' guidelines for the management of onychomycosis 2014. Br J Dermatol. 2014. Nov. № 171(5). P. 937-958. doi: $10.1111 / \mathrm{bjd} .13358$.

4. Dermatoscopy of onychomycosis / De Crignis and et al. Int J Dermatol. 2014. Feb. № 52(2). P. 97-99. doi: 10.1111/ijd. 12104 .

5. Dermoscopic patterns in patients with a clinical diagnosis of onychomycosis - results of a prospective study including data of potassium hydroxide $(\mathrm{KOH})$ and culture examination M.A. Jes s-Silva, R. Fernández-Martínez, R. Roldán-Marín, R. Arenas. Dermatol Pract Concept. 2015. Apr. № 5(2). P. 39-44. doi: 10.1111/bjd. 13358.

6. Dermoscopy and Onychomycosis: guided nail abrasion for mycological samples / D.L. Bet, A.L. Reis, N.D. Chiacchio, W. Belda Junior. Anais Brasileiros de Dermatologia. 2015. NovDec. № 90(6). P. 904-906. doi. 10.159/abd1806-4841.20154615,

7. Lencastre A., Lamas A., Sá D. Onychoscopy. Clin Dermatol. 2013. September October. № 31(5). P. 587-593. doi: https://doi.org/10.1016/j.clindermatol.2013.06.016.

8. Nail digital dermoscopy (onychoscopy) in the diagnosis of onychomycosis / B.M. Piraccini, R. Balestri, M. Starance, G.J. Rech. Eur Acad Dermatol Venereol. 2013. № 27(4). P. 509-513. doi: 10.1111/j.1468-3083.2011.04323.x

9. Nakamura R.C., Costa M. Dermatoscopic findings in the most frequent onychopathies: descriptive analysis of 500 cases. Int J Dermatol. 2012. № 51(4). P. 483-496. doi:10.1111/j.13654632.2010.04720.x

10. Piraccini B.M., Bruni F., Starace M. Dermoscopy of non-skin cancer nail disorders. Dermatol Ther. 2012. № 25. P. 594-602. doi: 10.1111/j.1529-8019.2012.01521.x.

11. Tulika Ashokkumar Yadav Uday Sharatchandra Khopkar. White Streaks: Dermoscopic Sign of Distal Lateral Subungual Onychomycosis. Indian J Dermatol. 2016. Jan-Feb. № 61(1). Pign of Distal Lateral Subungual Onychom $10.4103 / 0019-5154.174151$ дерматолога i, за нашим досвідом, корисним інструментом, який надає конкретні критерії для дерматоскопічної оцінки захворювань нігтів. За допомогою дерматоскопії, зокрема, можна побачити ознаки, які є винятковими для дистально-латерального піднігтьового оніхомікозу (DSLO), травматичного оніхолізису і дають змогу провести диференційну діагностику з іншими захворюваннями. Дерматоскопію слід розглядати як корисну, досить просту, швидку й недорогу методику діагностики в повсякденній практиці лікаря.

\section{References}

1. Kutasevich YaF, Oleynik IA, Belozorov AP. Sovremennyiy vzglyad na diagnostiku i lechenie dermatomikozov [A modern look at the diagnosis and treatment of dermatomycosis]. Meditsinskaya gazeta «Zdorov'ya Ukrayini 21 storlchchya». 2016;8(391). (In Russ.)

2. Allevato MA. Diseases mimicking onychomycosis. Clin Dermatol. 2010;28(2):164-177. doi:10.1016/j.clindermatol.2009.12.001.

3. Ameen M, Lear JT, Madan V. British Association of Dermatologists' guidelines for the management of onychomycosis 2014. Br J Dermatol. 2014;171(5):937-958. doi: 10.1111/bjd.13358. 4. De Crignis and etc. Dermatoscopy of onychomycosis. Int J Dermatol. 2014;52(2):97-99. doi: 10.1111/ijd.12104.

5. Jesús-Silva MA, Fernández-Martínez R, Roldán-Marín R, Arenas R. Dermoscopic patterns in patients with a clinical diagnosis of onychomycosis - results of a prospective study including data of potassium hydroxide $(\mathrm{KOH})$ and culture examination. Dermatol Pract Concept. 2015;5(2):39-44. doi: 10.1111/bjd. 13358

6. Bet DL, Reis AL, Chiacchio ND, Belda Junior W. Dermoscopy and Onychomycosis: guided nail abrasion for mycological samples. Anais Brasileiros de Dermatologia. 2015;90(6):904-906. doi: $10.1590 / \mathrm{abd} 1806-4841.20154615$.

7. Lencastre A, Lamas A, Sá D. Onychoscopy. Clin Dermatol. 2013;31(5):587-593. doi: https://doi.org/10.1016/j.clindermatol.2013.06.016

8. Piraccini BM, Balestri R, Starance M, Rech GJ. Nail digital dermoscopy (onychoscopy) in the diagnosis of onychomycosis. Eur Acad Dermatol Venereol. 2013;27(4):509-513. doi: 10.1111/j.1468-3083.2011.04323.x

9. Nakamura RC, Costa M. Dermatoscopic findings in the most frequent onychopathies: descriptive analysis of 500 cases. Int J Dermatol. 2012;51(4):483-496. doi:10.1111/j.13654632.2010.04720.x.

10. Piraccini BM, Bruni F, Starace M. Dermoscopy of non-skin cancer nail disorders. Dermatol Ther. 2012;25:594-602. doi: 10.1111/j.1529-8019.2012.01521.x

11. Tulika Ashokkumar Yadav, Uday Sharatchandra Khopkar. White Streaks: Dermoscopic Sign of Distal Lateral Subungual Onychomycosis. Indian J Dermatol. 2016;61(1):123. doi: 10.4103/0019-5154.174151

\title{
НОВЫЕ ВОЗМОЖНОСТИ ДИАГНОСТИКИ ОНИХОМИКОЗА С ПОМОЩЬЮ ДЕРМАТОСКОПИИ
}

\author{
А.С. Стовбыр
}

Национальная медицинская академия последипломного образования им. П.Л. Шупика

\section{Резюме}

Онихомикоз является одним из наиболее распространенных заболеваний ногтей, на которое приходится около $50 \%$ всех заболеваний ногтевого аппарата. Классические методы диагностики (микроскопия с КОН и культуральная диагностика) могут быть ложно отрицательными в 35\% случаев, что обусловливает необходимость поиска дополнительных диагностических методов. К таким методам можно отнести дерматоскопию. В настоящее время нет четкого алгоритма дерматоскопии, описанного и подтвержденного для оценки онихомикоза.

Целью работы было установление специфических дерматоскопических признаков грибкового поражения ногтей.

Результаты и выводы. Учитывая литературные данные и собственные наблюдения, пришли к выводу, что с помощью дерматоскопии, в частности, можно увидеть отличительные признаки, которые являются специфичными для дистально-латерального подногтевого онихомикоза (DSLO), травматического онихолизиса и позволяют провести дифференциальную диагностику с другими заболеваниями ногтевого аппарата.

Ключевые слова: онихомикоз, диагностика, дерматоскопия.

\section{NEW POSSIBILITIES IN THE DIAGNOSTICS OF ONYCHOMYCOSIS WITH DERMOSCOPY}

\section{G.S. Stovbyr}

P.L. Shupyk National Medical Academy of Postgraduate Education

\section{Abstract}

Onychomycosis is one of the most common nail diseases, accounting for about $50 \%$ of all diseases of the nail apparatus. Classical diagnostic methods (microscopy with $\mathrm{KOH}$ and cultural diagnostics) can be misleadingly negative in $35 \%$ of cases, which necessitates the search for additional diagnostic tools. Such methods include dermoscopy. There is currently no clear dermoscopy algorithm described and validated for the evaluation of onychomycosis.

The objective of the work was to establish the dermoscopic signs of fungal nail damage, their sensitivity and specificity.

Results and conclusions. Taking into account published data and our own observations it is possible to conclude that with the help of dermoscopy in particular it is possible to see the distinctive features that are exclusive to distal lateral subungual onychomycosis (DSLO), traumatic onycholysis, and allow to differentiate them with other nail diseases.

Key words: onychomycosis, diagnostics, dermoscopy. 